\title{
Expression profile and protein levels of placental products as indirect measures of placental function in in vitro-derived bovine pregnancies
}

\author{
Marcelo Bertolini, Charles R Wallace ${ }^{1}$ and Gary B Anderson \\ Department of Animal Science, University of California, Davis, Davis, California 95616, USA and ${ }^{1}$ Animal and \\ Veterinary Science, University of Maine, Orono, Maine 04469, USA
}

Correspondence should be addressed to G B Anderson; Email: gbanderson@ucdavis.edu

\begin{abstract}
Bovine conceptus development and its association with placental proteins present in maternal, foetal and neonatal plasma and foetal (amniotic and allantoic) fluids were investigated in in vivo- and in vitro-produced (IVP) concepti and newborn calves. Females were superovulated to obtain control embryos, whereas IVP embryos were derived from established in vitro procedures. Pregnant animals were slaughtered on days 90 or 180 of gestation or allowed to develop to term for the assessment of physical traits. Foetal, maternal and neonatal blood and foetal fluids were collected for the determination of bovine placental lactogen (bPL) and bovine pregnancy-specific protein B (bPSPB) concentrations. Placental transcripts for bPL and bPSPB, determined by quantitative RT-PCR, were elevated in IVP placentomes. No major physical differences were observed between groups on day 90, but concentrations of bPL and bPSPB were higher in foetal plasma and allantoic fluid of IVP concepti in day 180 pregnancies, which were correlated with larger uterine and conceptus traits. Maternal concentrations of bPL in IVP pregnancies were lower than controls during the last 8 weeks of gestation, to become similar as parturition approached. Newborn IVP calves and foetal membranes were larger and displayed higher concentrations of plasma bPL than controls (10 and $60 \mathrm{~min}$ after birth). Our results indicated that differential patterns of secretion of bPL and bPSPB into the maternal and foetal systems occurred at distinct stages of gestation, and these were associated with altered conceptus development after in vitro embryo manipulations, indirectly demonstrating deviations in placental function in IVP pregnancies. Reproduction (2006) 131 163-173
\end{abstract}

\section{Introduction}

With the onset of the trophoblast apposition to the endometrium during the process of bovine placenta formation and development, large granulated cells, the trophoblast binucleate cells (BCs), migrate from the trophectoderm to fuse with uterine epithelial cells (Wooding 1992), forming short-lived trinucleate cells. This phenomenon occurs throughout pregnancy in cattle, but the number and period of existence of trinucleate cells decline towards the end of gestation (Wooding 1992, Green et al. 2000). Binucleate cells comprise about $20 \%$ of the trophoblast cells and are responsible for hormones and bioactive products important for the regulation of foetal growth and development (Anthony et al. 1995, Green et al. 2000, Schlafer et al. 2000). The contents of the membranebounded secretory granules of BCs are released by exocytosis towards the maternal capillary bed, reaching the maternal blood system (Wooding 1992). Many proteins are produced by the BCs, including placental lactogen
(PL) and a range of glycoproteins (Wooding 1992), such as pregnancy-specific protein B (PSPB) (Butler et al. 1982).

$\mathrm{PL}$ lactogen is a member of the growth hormone $(\mathrm{GH}) /$ prolactin (PRL) gene family synthesized and stored in secretory granules of the trophoblast BCs (Byatt et al. 1992a, Wooding 1992, Gootwine 2004). Although its function and secretory control are not completely understood, in vivo and in vitro studies have suggested PL to have multiple somatogenic (GH-like) and lactogenic (PRLlike) biological effects, depending on the species, such as placental angiogenesis, maternal and foetal intermediate metabolism, mammary gland development and function, ovarian and placental steroidogenesis, growth rate and luteal function (Patel et al. 1996, Pedersen et al. 1998, Gregoraszczuk et al. 2000, Corbacho et al. 2002, Gertler \& Djiane 2002, Gootwine 2004). Bovine (b) PL is more structurally similar to PRL than $\mathrm{GH}$ and is secreted into both the maternal and foetal systems (Gootwine 2004), with a decrease in foetal concentrations during the course of gestation and a peak in maternal plasma during the last 
trimester of pregnancy (Byatt et al. 1992a). It has been postulated that bPL recognizes homologous and heterologous somatogenic and lactogenic receptors, acting through components of the insulin-like growth factor system, which may modulate foetal growth (Byatt et al. 1992a, Anthony et al. 1995).

PSPB was first isolated from bovine placental tissues, as a product of the BCs of the trophoblastic ectoderm (Butler et al. 1982). Several isoforms of pregnancy-associated glycoproteins (PAG) from foetal cotyledons showing similarities with PSPB have been isolated (Zoli et al. 1991). Currently, PSPB is also known as PAG-1, being inactive members of the aspartic proteinase family (Xie et al. 1991, Lynch et al. 1992). Gene and cDNA sequencing have shown identical homology between PSPB and PAG-1, with both proteins differing only in glycosylation and sialic acid contents (Xie et al. 1991, 1995, Lynch et al. 1992). Concentrations of bPSPB in maternal plasma can be detected from early stages of gestation, during early placentation, to increase gradually throughout pregnancy and reach peak values immediately before parturition (Sasser et al. 1986, Kiracofe et al. 1993). Despite the unknown function and control of PSPB secretion, many potential biological functions have been suggested based on in vivo and in vitro effects, including prostaglandin release by the endometrium, implantation, immunotolerance of the conceptus as a tissue alograft and uterine remodelling after parturition, among others (Del Vecchio et al. 1990, 1995, 1996, Kiracofe et al. 1993, Austin et al. 1999, Tefera et al. 2001). Both PAG-1 and PSPB diagnostic assays have been developed for early plasma diagnosis of pregnancy in cattle and other ruminants (Sasser et al. 1986, Zoli et al. 1991, Green et al. 2000).

The amounts of BC products in maternal circulation appear to be associated with placental mass, foetal number and neonatal birth weight, and have been postulated to be an index for conceptus viability and pregnancy normalcy in cattle (Byatt et al. 1992a, Patel et al. 1995, 1996, 1997, Vasquez et al. 1995, Szenci et al. 1998, 2003, Tefera et al. 2001, Ravelich et al. 2004). Associations between abnormal placental and foetal development after in vitro embryo manipulations have been suggested to play a key role in the occurrence of high birth weights. Disturbances in placentation may at least partially affect the pattern of foetal growth (Hill et al. 2000, 2001, Bertolini et al. 2002a, Hashizume et al. 2002, Reik et al. 2003). Disruptions in $\mathrm{BC}$ function may compromise the viability and growth of the developing conceptus. Since significant spatial and temporal differences in the expression in the more than 20 identified bPAG cDNA isoforms appear to occur during bovine pregnancy (Green et al. 2000), distinct isoforms of the PAG-1 group may be more useful for the diagnosis of pregnancy and to predict deviations from normality. This study describes results using the same animals and samples as in previous reports (Bertolini et al. 2002a,b, 2004) to further investigate bovine foetal and placental development and their association with placental transcripts
(bPL and bPAG-1) and plasma and foetal fluid protein concentrations (bPL and bPSPB) in in vivo-produced and in vitro-produced (IVP) concepti and newborn calves for use as potential biological markers for altered conceptus development after in vitro embryo manipulations.

\section{Materials and Methods}

All chemicals used in the experiments were from Sigma Chemical Co. (St Louis, MO, USA), unless stated otherwise. All animals were from a similar genetic background and origin, and animals in each experiment were maintained under the same environmental, nutritional and general management conditions during the experiments. All procedures conformed to the Guidelines for Care and Use of Laboratory Animals, National Research Council and were approved by the Institutional Animal Care and Use Committee of the University of California, Davis. In this study, the terms bPAG-1 or bPSPB refer specifically to transcripts or protein respectively.

\section{Embryo production, embryo transfer and pregnancy diagnosis}

IVP and in vivo-produced (controls) Bos taurus embryos were generated according to our established procedures, as previously described (Bertolini et al. 2002a,b, 2004). We have adopted an IVP system known to induce, at a relatively high frequency, the appearance of symptoms of the Large Calf Syndrome (Behboodi et al. 1995, Bertolini et al. 2002a, 2004). Bovine cumulus-oocyte complexes from Angus-Hereford cross females were obtained either from a commercial source (Bomed Inc., Madison, WI, USA) or from a regional slaughterhouse. Donor females (Angus or Angus-Hereford crosses) were superovulated for the production of control embryos. Embryos were nonsurgically recovered by uterine flushing on day 7 of development (artificial insemination $=$ day 0 ). The same Angus sires were used for production of both control and IVP embryos. Blastocysts and expanded blastocysts from both embryo production systems (control and IVP) were nonsurgically transferred to synchronous $( \pm 12 \mathrm{~h})$ recipients on day 7 of development. Single embryos were transferred to recipients for the group of animals slaughtered on days 90 and 180, whereas one (in vivo singleton, in vitro singleton) or two (in vitro twin) embryos were transferred for the group of females allowed to carry pregnancies to term (Bertolini et al. 2002a, 2004). Pregnancy and foetal gender diagnoses were carried out by means of ultrasonography, per rectum, on days 27-30 and 58-60 of gestation respectively (Bertolini et al. 2002a, 2004).

\section{Conceptus development and sample collection}

Detailed morphometric, morphological and physiological data regarding foetal and placental development during pregnancy and after delivery for the group of recipients 
slaughtered on days 90 and 180 or allowed to carry pregnancies to term have been described previously (Bertolini et al. 2002a, 2004).

\section{Days 90 and 180 of gestation}

A group of pregnant females was slaughtered on days 90 or 180 of gestation $(n=4$ in control and $n=5$ IVP pregnancies for each day) for the collection of pregnant uteri and their respective foetuses and placental membranes. Pregnant females were allocated to each harvest day according to foetal gender and foetal viability after ultrasound examinations. In the control group $(n=8)$, animals carrying three females and one male were assigned to each harvest day (90 and 180) and, in the IVP group $(n=10)$, female recipients sustaining pregnancies with four females and one male were harvested on day 90, and recipients carrying three females and two males on day 180 of gestation. Foetal gender diagnoses performed on day 60 of pregnancy were all confirmed after harvest. Upon slaughter, reproductive tracts were excised and immediately weighed. Maternal blood samples were obtained at exsanguination. Following uterine dissection, foetal blood was collected by cardiopuncture, and total allantoic and amniotic fluid volumes were measured and sampled. Maternal and foetal blood, and amniotic and allantoic fluids were centrifuged, and plasma and fluids were frozen and stored at $-80^{\circ} \mathrm{C}$ pending analyses. Individual placentomes were weighed and measured (length and width) for estimation of the total gross surface area (SA). Placentomes were also classified into four categories by type according to gross morphological appearance, as follows: (A) engulfing mushroom-like, (B) sub-engulfing mushroom-like, (C) flattened, non-engulfing and (D) semi-convex placentomes (Fig. 1a). Sample placentomes from the region immediately surrounding the foetuses were excised along their longitudinal axis, and pieces containing both maternal and foetal boundaries were snap-frozen in liquid nitrogen, stored at $-80^{\circ} \mathrm{C}$ and ultimately used for measurement of the relative transcription of genes of placental products (bPL and bPAG-1), as described below.

\section{Pregnancy and postpartum}

Birth weights and physical traits were recorded upon delivery; foetal membranes were weighed, dissected and measured, as previously reported (Bertolini et al. 2002a). Maternal blood samples were taken from pregnant females on day 30 of gestation and continued to be collected on a weekly basis throughout pregnancy; additional maternal samples were obtained at delivery and $24 \mathrm{~h}$ after delivery. Neonatal venous blood samples were collected five times during the first $24 \mathrm{~h}$ ex utero: within the first $10 \mathrm{~min}$, which reflected intrauterine conditions, and at 1 , 6, 12 and $24 \mathrm{~h}$ after birth. Blood samples were taken by jugular venipuncture in heparinized tubes. Upon (a)
(A)

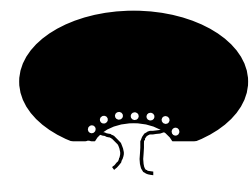

(B)

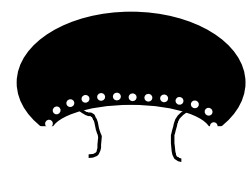

(C)

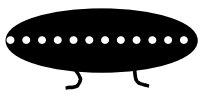

(D)

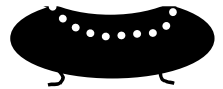

(b)
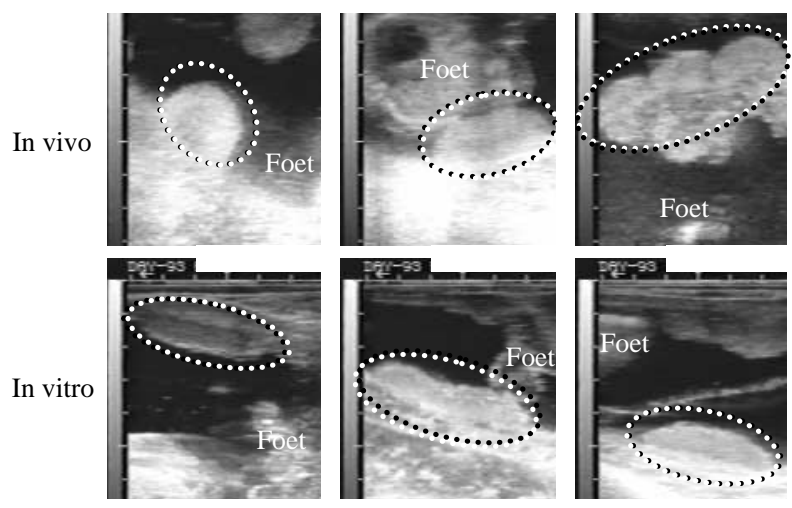

(c)

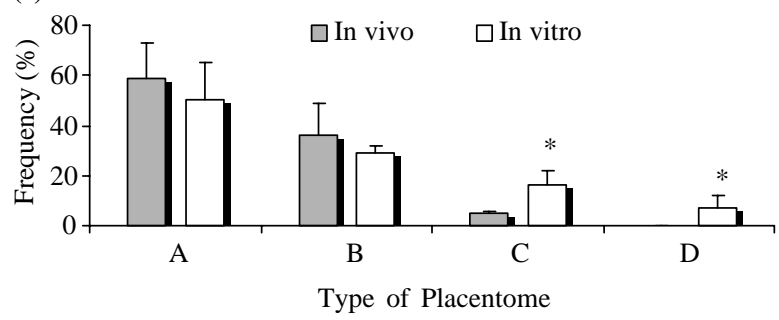

Figure 1 Morphological characteristics of Bos taurus placentomes during gestation. (a) Classification of placentomes by type according to anatomical shapes on day 180 of gestation: (A) engulfing mushroom-like, (B) sub-engulfing mushroom-like, (C) flattened, nonengulfing and (D) semi-convex placentomes (adapted from Vatnick et al. (1991), Penninga \& Longo (1998) for sheep and from Laven \& Peters (2001) and the cotyledon-caruncle anchoring mechanism hypothesis of Eiler \& Hopkins (1993) both for cattle); white-dotted line in the sketch of each placentome type represents the external boundary between foetal and maternal tissues. (b) Sonograms of placentomes (within ellipses) immediately surrounding the foetuses (Foet) of in vivo- (top row) and in vitro-derived (bottom row) pregnancies on day 93 of gestation (scale on left of the screen in each sonogram is in $\mathrm{cm}$ ). (c) Frequency of distribution (\%) of placentomes classified by type between in vivo- and in vitro-derived Bos taurus pregnancies on day $180 . * P<0.05$, for each placentome type.

collection, blood samples were immediately centrifuged and plasma was frozen at $-20^{\circ} \mathrm{C}$ pending analyses.

\section{bPL and pPSPB measurements in plasma and foetal fluids}

Concentrations of bPL and bPSPB were determined by radioimmunoassay, in duplicates of maternal, foetal and 
neonatal plasma, and amniotic and allantoic fluids, according to established procedures by Wallace (1993) for bPL and Sasser et al. (1986) for bPSPB (BioTracking, Moscow, ID, USA). In this study, intra- and interassay coefficients of variation were $4.9 \%$ and $12.0 \%$ for $\mathrm{bPL}$ and $10.2 \%$ and $15.7 \%$ for bPSPB respectively.

\section{Relative abundance of bPL and bPAG-1 transcripts in day-90 and -180 placentomes}

A real-time TaqMan PCR (Applied Biosystems, Foster City, CA, USA) was optimized to quantify transcripts for bPL and bPAG-1 genes, following procedures described by Bertolini et al. (2002 b, 2004). The analysis was performed at the Lucy Whittier Molecular Core Facility, School of Veterinary Medicine, University of California, Davis. Quantitative analyses of bovine cDNA from control and IVP day-90 and day-180 placentomes were performed in comparison with the endogenous control (glyceraldehyde3-phosphate dehydrogenase; GAPDH), and were amplified in an automated laser-based fluorometer (7700 ABI PRISM Sequence Detection System; Applied Biosystems). Final quantification was done using the comparative $C_{T}$ method (Leutenegger et al. 2000). All samples were included in each assay, in single reactions, with one assay per transcript. Sequences of primers and probes for the transcripts are shown in Table 1.

\section{Statistical analyses}

Data analyses were done in Proc GLM of SAS (SAS Institute, Cary, NC, USA). Data obtained after slaughter (days 90 and 180) were compared by ANOVA, considering group (in vivo, in vitro), day $(90,180)$ and gender (male, female) as main effects, with foetal weight also used as the covariate by ANCOVA. Data obtained in groups of animals that carried pregnancies to term were analysed by the repeated measures procedures of SAS (group and time as main effects with animal nested within group). Pairwise comparisons were performed by least square means (LSM). Data regarding the distribution of placentome size and type were analysed by the Kruskal-Wallis test (Minitab Inc., State College, PA, USA). A Pearson's correlation test was used for analysis of relationships between traits, also using corrected values for the covariate, as well as the other fixed effects of group, time and animal.

\section{Results}

For the group of animals slaughtered on days 90 or 180 of gestation, pregnancy rates on day 27 and pregnancy losses from day 27 of gestation (pregnancy diagnosis) to day 60 (foetal gender diagnosis) for the control and IVP groups were 33\% (10/30) and 32\% (27/84), and 10\% (1/10) and $63 \%(17 / 27)$ respectively. One additional control pregnancy was lost on day 160 of gestation. For the group of animals allowed to carry pregnancies to term, pregnancy rates on day 30 were 43\% (10/23), 32\% (9/28) and 50\% (5/10), and pregnancy losses throughout gestation were $40 \%(4 / 10), 33 \%(3 / 9)$ and $40 \%$ (2/5), for the in vivo singleton (control), in vitro singleton and in vitro twin groups respectively. No differences were observed between groups in both pregnancy rates (20/53 and 41/122 for the control and IVP groups respectively) and occurrence of losses after day 45 of gestation (2/20 and 4/41 for the control and IVP groups respectively), considering both experiments combined. However, losses were 2.2-fold higher $(P<0.05)$ in the IVP group $(18 / 41)$ than in controls $(4 / 20)$ between days 30 and 44 of gestation.

Data regarding the comparison of physical traits between in vivo- and in vitro-derived concepti, newborn calves and term foetal membranes have been described previously (Bertolini et al. 2002a, 2004) and are summarized in Table 2. Placentomes were longer, wider and thinner (Fig. 1b) in the IVP group (Bertolini et al. 2004), and distribution of placentome types was also different between groups $(P<0.05)$ on day 180 of pregnancy, with the occurrence of more uncommon types (C and D) in IVP pregnancies (Fig. 1c). The presence of such types, primarily type C, in controls was usually associated with small placentomes located in the non-foetal horn, whereas these placentome types were randomly present in both uterine horns of IVP pregnancies in a wide size range. The difference in individual placentome size in the IVP group on day 90 of gestation, particularly in the foetal horn, was correlated with significantly higher $(P<0.05)$ concentrations of bPL and bPSPB in foetal plasma and allantoic

Table 1 Sequence of PCR primers, TaqMan probes and GenBank accession code numbers for transcripts analysed in control and IVP day-90 and day-180 Bos taurus placentomes.

\begin{tabular}{llcll}
\hline Transcripts & Primers sequences $\left(5^{\prime}-3^{\prime}\right)^{\mathrm{a}, \mathrm{b}}$ & Length & Probe sequences $\left(5^{\prime}-3^{\prime}\right)^{\mathrm{b}}$ & Acession no. \\
\hline bGAPDH & F-GGGCGTGAACCAACGAGAAGTATAA & 120 & $\begin{array}{l}\text { ATACCCTCAAGATTG } \\
\text { CAGCAATGCCTCCT }\end{array}$ & AF022183 \\
bPL & $\begin{array}{l}\text { R-CCCTCCACGATGCCAAAGT } \\
\text { F-GTGGAAATGATACAAAAAAGGGTTCAT }\end{array}$ & 100 & AGAACGAGCCCTATCCAGTGTGGTCAGA & M33268 \\
bPAG-1 & $\begin{array}{l}\text { R-CATCCTCATCGTCTGCTGTCA } \\
\text { F-GAGTGCATAGTCAAAATACCTCTAAGGA }\end{array}$ & 110 & TGAAGACCATGAGAAATGTCGTCAGTGGA & L27833 \\
& R-TGGGACAGACTGTAAGCATGCT & & & \\
\hline
\end{tabular}

aPrimer orientations: $\mathrm{F}=$ forward; $\mathrm{R}=$ reverse.

${ }^{b}$ Exon-exon junctions are italicized. 
Table 2 Physical measurements of Bos taurus conceptus traits on days 90 and 180 of gestation, and on term foetal membranes and neonates between in vivo- and in vitro bovine embryo production systems (LSM \pm S.E.M).

\begin{tabular}{|c|c|c|c|c|c|c|c|}
\hline \multirow[b]{2}{*}{ Traits } & \multicolumn{2}{|c|}{ 'Day 90' } & \multicolumn{2}{|c|}{ 'Day $\mathbf{1 8 0}^{\prime 1}$} & \multicolumn{3}{|c|}{ Term $^{2}$} \\
\hline & In vivo & In vitro & Invivo & In vitro & In vivo/singlets & In vitro/singlets & In vitro/twins \\
\hline Body weight (kg) & $0.146 \pm 0.013^{a}$ & $0.173 \pm 0.008^{a}$ & $6.462 \pm 0.180^{b}$ & $7.163 \pm 0.399^{c}$ & $32.5 \pm 5.1^{d}$ & $43.2 \pm 7.4^{\mathrm{c}}$ & $31.5 \pm 5.4^{\mathrm{d}}$ \\
\hline Femoral length $(\mathrm{mm})$ & $23.3 \pm 1.4^{\mathrm{a}}$ & $24.6 \pm 0.3^{\mathrm{a}}$ & $100.3 \pm 1.5^{\mathrm{b}}$ & $108.0 \pm 1.2^{\mathrm{C}}$ & $209.0 \pm 8.0^{\mathrm{d}}$ & $233.0 \pm 12.0^{\mathrm{c}}$ & $208.0 \pm 12.0^{\mathrm{d}}$ \\
\hline Weight $(\mathrm{kg})^{3}$ & $0.124 \pm 0.037^{a}$ & $0.085 \pm 0.020^{\mathrm{a}}$ & $2.23 \pm 0.03^{b}$ & $2.90 \pm 0.26^{\mathrm{c}}$ & $4.30 \pm 1.10^{\mathrm{d}}$ & $5.90 \pm 1.90^{\mathrm{d}}$ & $8.90 \pm 0.60^{c}$ \\
\hline Gross S A $(\mathrm{dm})^{2,4}$ & $2.01 \pm 0.47^{\mathrm{a}}$ & $2.92 \pm 0.29^{\mathrm{a}}$ & $24.60 \pm 1.29^{b}$ & $32.36 \pm 5.40^{b}$ & $41.0 \pm 10.0^{\mathrm{C}}$ & $49.0 \pm 9.0^{c}$ & $51.0 \pm 16.0^{\mathrm{C}}$ \\
\hline
\end{tabular}

Data in the same row without common superscript letters differ significantly. $P<0.05$.

${ }^{\mathrm{a} D}$ Data adapted from Bertolini et al. (2004).

${ }^{\mathrm{b}}$ Data adapted from Bertolini et al. (2002a).

'Placentome (days 90 and 180) or foetal membrane (term) weight.

${ }^{\mathrm{d}} \mathrm{SA}=$ surface area, referring to placentome (days 90 and 180) or cotyledonary (term) surface area. $P=0.0636$ for day-180 female concepti.

fluid, and relative abundance of placentome transcripts for bPL and bPAG-1 in IVP concepti (Fig. 2a and b). On day 180, the relative abundance of placental transcripts for bPL and bPAG-1 (Fig. 2a and b) and uterine, foetal and placental physical component weights (Bertolini et al. 2004, Table 2) were larger in IVP pregnancies than in controls. Concentrations of bPSPB in the allantoic fluid of IVP pregnancies were 2.9-fold lower than controls (Fig. 2b) but, since day-180 IVP pregnancies had a 2- to 3-fold larger allantoic fluid volume than controls (Bertolini et al. 2004), total bPL and bPSPB in the allantois were higher and similar to controls respectively (Fig. 2c).

In general, IVP pregnancies had a higher placental transcriptional activity (bPL and bPAG-1) and foetal plasma concentrations of bPL and bPSPB than controls $\left(P_{\text {group }}<0.05\right)$, irrespective of the gestational day (90 or 180), as shown in Fig. 2. Temporally, concentrations of bPL were higher in the uterine compartments (foetal plasma and fluids) than in maternal plasma, apart from the experimental group $\left(P_{\text {day }}<0.05\right)$. In addition, maternal concentrations of bPL and bPSPB were higher on day 180 than on day $90\left(\mathrm{P}_{\text {day }}<0.05\right)$, but lower in foetal plasma (bPL and bPSPB) and amniotic fluid (bPL). Positive correlations were observed between BPL and bPAG-1 transcripts $(r=0.824, P<0.05)$, between bPL and bPSPB concentrations in the same fluid type (maternal plasma, $r=0.715$, foetal plasma, $r=0.635$, amniotic fluid, $r=0.505, \quad P<0.05$, except in allantoic fluid), and between maternal concentrations of bPL and bPSPB $(r>0.850, P<0.05)$, and with glucose and fructose accumulations $(r>0.650, P<0.05)$ in the uterine compartments (data not shown, Bertolini et al. 2004). Positive correlations were observed also between conceptus component weights, substrate (glucose and fructose, data not shown) accumulations and bPAG-1 transcripts $(r>0.600$, $P<0.05)$.

Plasma concentrations of bPL throughout gestation in pregnant females carrying in vivo singleton, in vitro singleton and in vitro twin concepti are illustrated in Fig. 3. Three distinct phases can be visualized in the weeks preceding parturition, based on the variation in bPL concentrations among groups (Fig. 3). In phase I (weeks 39 and
24 prepartum), no differences in concentrations of maternal plasma bPL were observed between groups. Then, in phase II (week 23 to week 8-9 prepartum), concentrations of maternal bPL were significantly higher in the in vitro twin group $(P<0.05)$. In phase III (week 8-9 to week 1 prepartum), maternal concentrations in the in vitro singleton group were lower $(P<0.05)$, but similar to controls and the in vitro twin group as parturition approached. At delivery, concentrations of maternal plasma bPL were significantly different between groups (in vivo singletons $<$ in vitro singletons $<$ in vitro twins, $P<0.05$ ), to become similar $24 \mathrm{~h}$ after parturition.

Concentration profiles for bPSPB between groups followed the same pattern as that seen for bPL, as depicted in Fig. 4, for a steady increase in plasma concentrations from early to late pregnancy, with a decline following parturition. The in vitro singleton group had lower bPSPB concentrations than controls and the in vitro twin group in the week and the day immediately preceding and following parturition respectively $(P<0.05)$, but no other significant differences were observed between groups at any further stage of gestation examined.

Newborn plasma concentrations of bPL $(P<0.05)$ in IVP calves, either singletons or twins, were 2- to 4 -fold higher immediately after birth (10 and $60 \mathrm{~min})$ than controls, to become similar afterwards (Fig. 5a). Plasma concentrations of bPSPB tended to be higher $(P<0.08)$ and became significantly higher $(P<0.05)$ in the in vitro singleton group $60 \mathrm{~min}$ and $24 \mathrm{~h}$ after birth respectively (Fig. 5b). Concentrations of bPL and bPSPB in the first 60 min postpartum were positively correlated with neonatal and foetal membrane physical traits $(r>0.800$, $P<0.05)$, and correlated with neonatal plasma fructose concentrations (data not shown, Bertolini et al. 2004).

\section{Discussion}

Changes in placental development and function in IVP pregnancies derived either from in vitro fertilization (IVF) or somatic cell nuclear transfer procedures have been associated with the delivery of larger calves and the appearance of aberrant foetal membranes (Hill et al. 2000, 

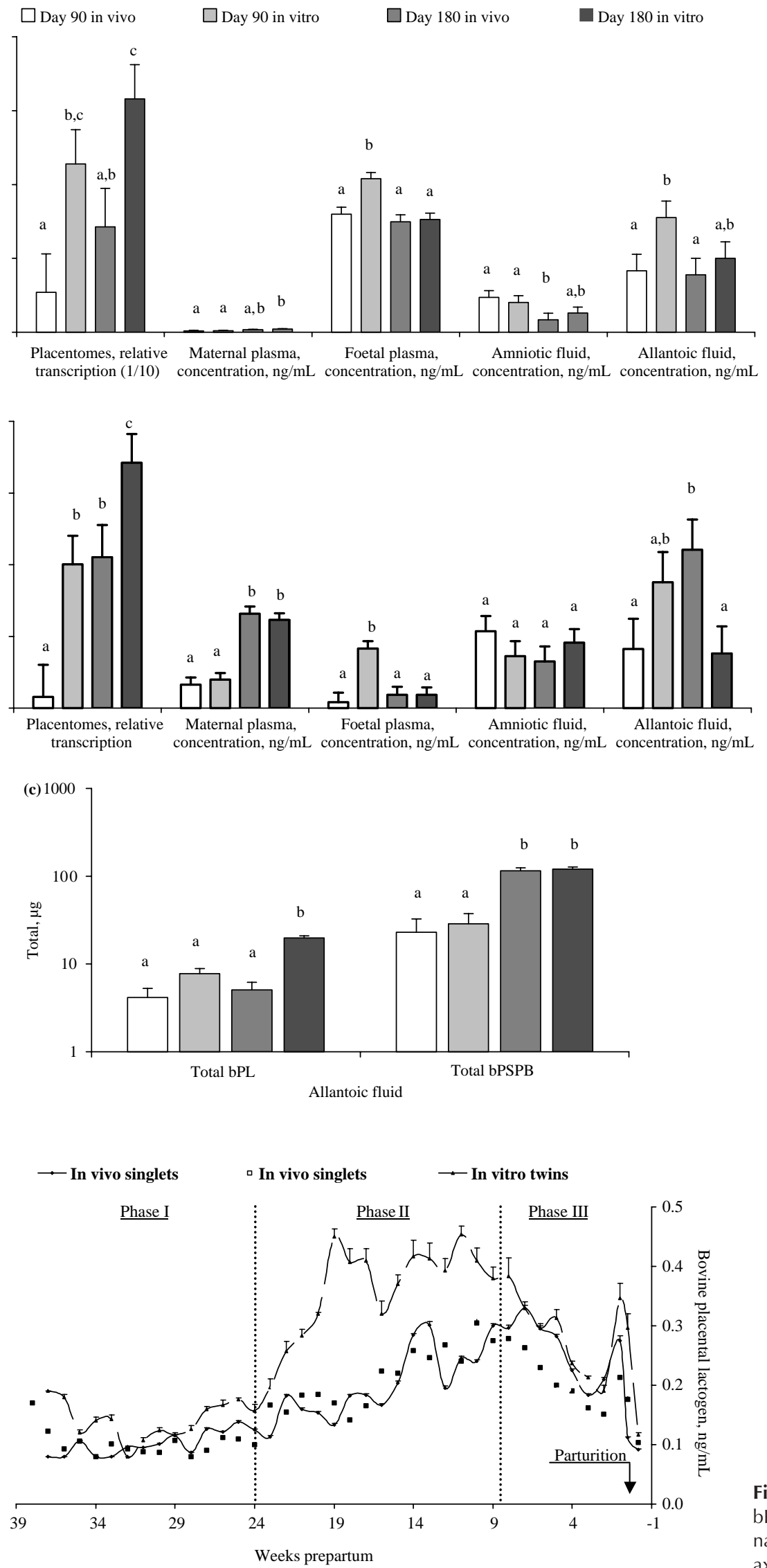

Reproduction (2006) 131 163-173
Figure 2 Placental relative transcription and plasma and fluid concentrations $(\mathrm{ng} / \mathrm{ml})$ for in vivo- and in vitro-produced bovine pregnancies on days 90 and 180 of gestation (LSM \pm S.E.M.). (a) bPL, (b) bPAG-1 and bPSPB and (c) total $\mathrm{BPL}$ and $\mathrm{BPSPB}$ in the allantoic fluid. Columns without common superscripts differ $(P<0.05)$.
Figure 3 Maternal plasma concentrations $(\mathrm{ng} / \mathrm{ml})$ of bPL for in vivo- and in vitro-produced bovine pregnancies throughout gestation (LSM \pm S.E.M.); the $x$ axis is downwards, in weeks prepartum. 


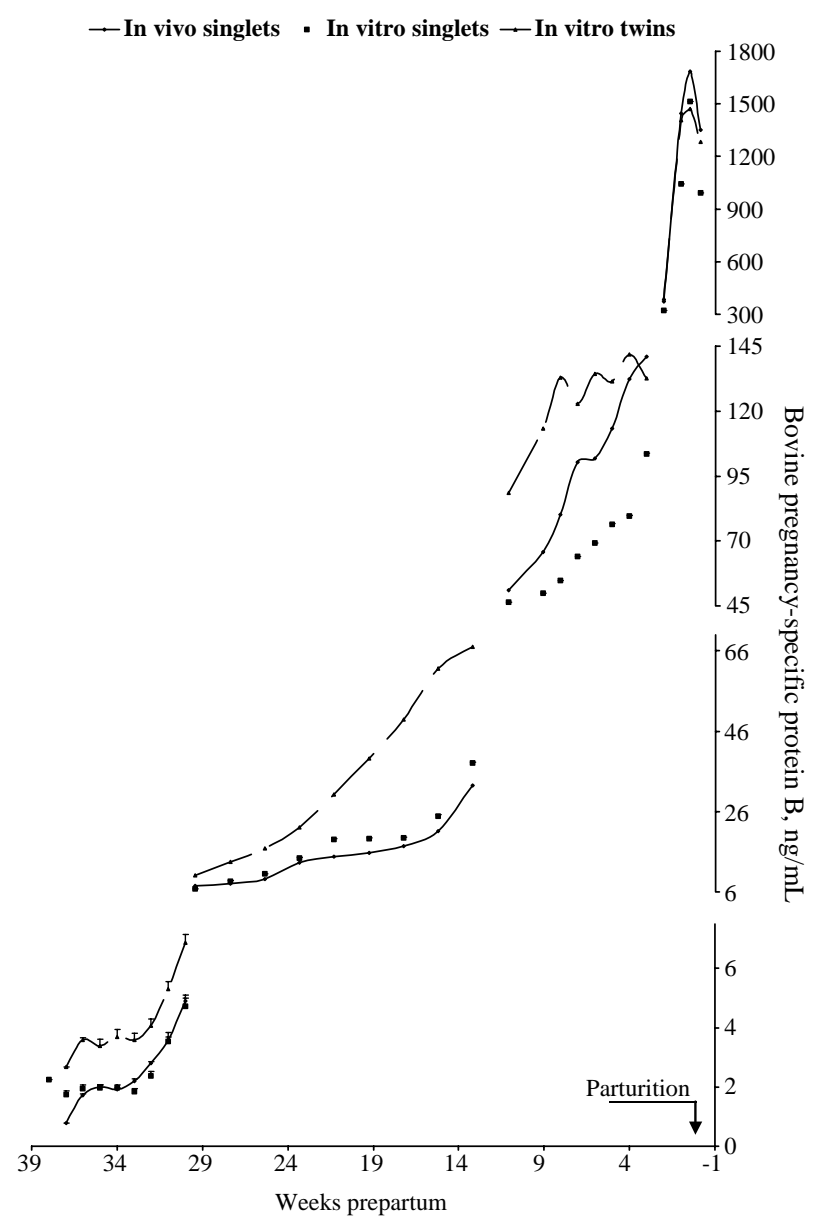

Figure 4 Maternal plasma concentrations $(\mathrm{ng} / \mathrm{ml})$ of bPSPB for in vivo- and in vitro-produced bovine pregnancies throughout gestation (LSM \pm S.E.M.). Note the distinct scales in the $y$ axis; the $x$ axis is downwards, in weeks prepartum.

2001, Bertolini et al. 2002a, 2004, Hashizume et al. 2002, Reik et al. 2003), but cause-and-effect relationships between morphological and functional changes have been difficult to attain. We have already demonstrated that IVP pregnancies contain larger concepti toward the end of the second trimester of pregnancy. This was associated with disturbances in placental development and function, including substrate transfer and accumulation in the uterine compartments (Bertolini et al. 2004), along with differences in the synthetic protein capacity by BCs, as seen in this study, which culminate in the delivery of larger calves (Bertolini et al. 2002a). Placental BC products, such as bPL, bPSPB and bPAG-1, have been suggested as useful markers for embryonic or placental health, pregnancy normalcy and embryonic mortality, and for the prediction of abnormal conceptus development and postpartum pathological events (Patel et al. 1997, Szenci et al. 1998, 2003, Tefera et al. 2001). Such BC products or the relative abundances of their placental transcripts have already been used in an attempt to detect or predict conceptus abnormalities after in vitro embryo manipulations (Vasquez et al.
1995, Schmidt et al. 1996, Hill et al. 2000, Hashizume et al. 2002, Heyman et al. 2002, Ishiwata et al. 2003, Hoffert et al. 2004, Patel et al. 2004a, Ravelich et al. 2004), and results from these studies have increasingly contributed to the understanding of those abnormalities.

In this study, placental and foetal membrane weight and placental and cotyledonary SAs were greater in IVP pregnancies, and both mass and SAs increased as a function of the increase in placentome length and width, but placentomes were thinner at both days 90 and 180 of gestation. Changes in placental morphology and deviations in the morphological distribution of the placentome type (fewer types $A$ and $B$ and increased unusual $C$ and $D$ types) were readily detectable in the first and second trimester of gestation in IVP pregnancies (Fig. 1). Such variations in placentome types may reflect anatomical, histological and functional differences in development, and such changes may ultimately influence placental transport efficiency, function, metabolism and synthetic capacity. Under physiological conditions, the placenta grows faster than the foetus in early pregnancy but slower after mid-gestation, when foetal weight surpasses that of the placenta (Eley et al. 1978, Prior \& Laster 1979, Reynolds et al. 1990). Morphologically, the bovine placenta is considered fully developed at mid- to late gestation, but foetal villous trees continue to develop (branching pattern) and rearrange (spatial relationship between endothelium and trophoblast) in placentomes until near term, increasing the villous $\mathrm{SA}$, which will also accommodate foetal demands for growth towards the end of gestation (Leiser et al. 1997). However, the placental tissue holds a great plastic capacity in facing unusual, adverse circumstances. Maternal dietary restriction or hypoxia in early gestation in cattle and sheep can initially impair such a standard pattern of placental growth (Penninga \& Longo 1998, Perry et al. 1999, Wallace et al. 1999, Symonds et al. 2001) but, once dietary intake is restored to normal, a placental and foetal growth compensatory enhancement is observed. A coincidental aspect of these findings with our studies is that IVP concepti were significantly smaller during the period of placentation to the early foetal stage (up to day 58 of gestation), which appeared to have preceded a subsequent compensatory growth initiated with the placental tissue and followed by the foetus (Bertolini et al. 2002a). A hormonal effect of PSPB has been demonstrated in inducing the in vitro release of an $\alpha$ chemokine (granulocyte chemotactic protein-2) by the endometrium, which may be relevant for implantation and placental angiogenesis (Austin et al. 1999). Bovine placental PAG-1 and foetal plasma PSPB were elevated in the IVP group at a time at which placental compensatory growth was already detectable (day 90).

The amounts of placental products in maternal circulation appear to be associated with placental and foetal masses, including foetal number and neonatal birth weight, and with pregnancy normalcy (Byatt et al. 1992a, Patel et al. 1995, 1997, Vasquez et al. 1995, Tefera et al. 

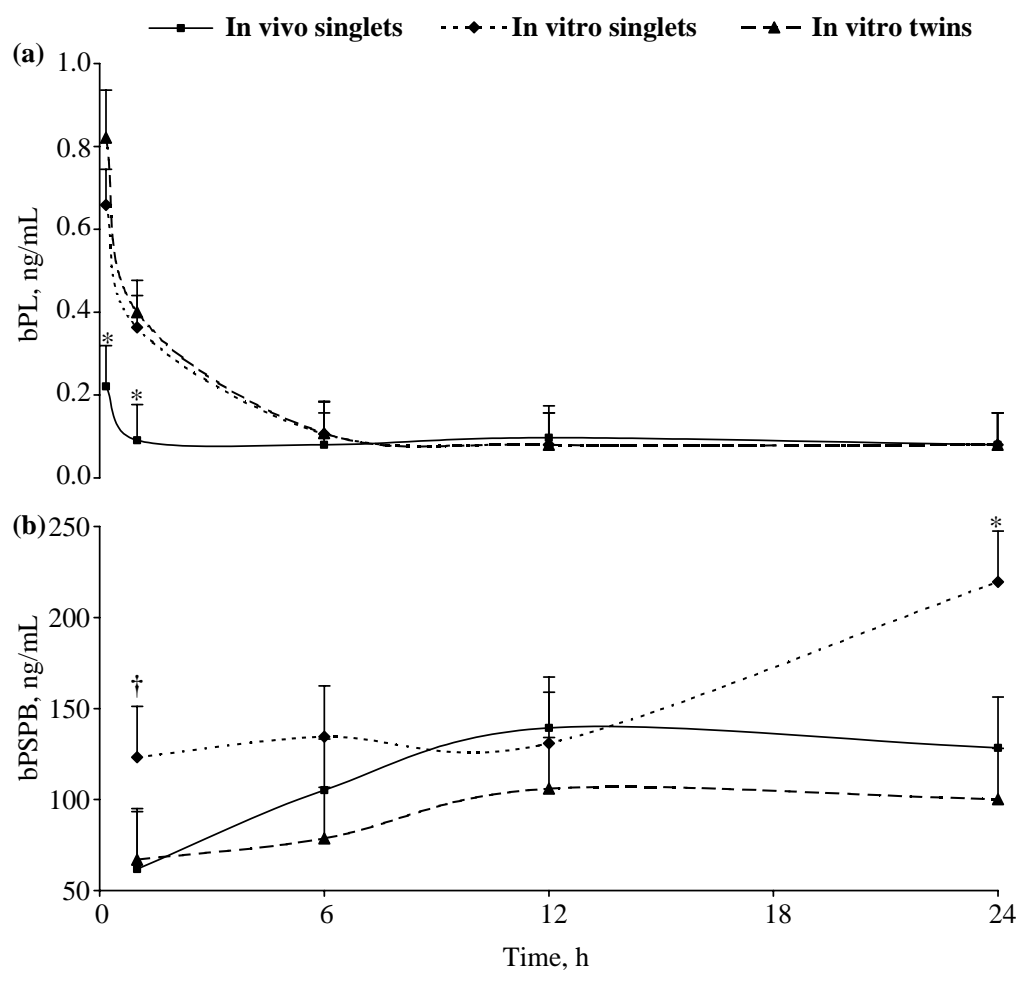

Figure 5 Neonatal plasma concentrations $(\mathrm{ng} / \mathrm{ml})$ for in vivo singleton, in vitro singleton and in vitro twin calves in the first $24 \mathrm{~h}$ after birth (LSM \pm S.E.M.). (a) bPL and (b) bPSPB. $* P<0.05,+P<0.1$.
2001, Gootwine 2004). In this study, concentrations of maternal and foetal plasma bPL followed similar trends reported by Hossner et al. (1997), Holland et al. (1997) and Patel et al. (1996), but concentrations of bPL and bPSPB in foetal plasma were correlated with conceptus physical traits and with one another in plasma and fluids. Anthony et al. (1995) suggested that a relationship exists between ovine PL gene expression and the rate of ovine $\mathrm{PL}$ appearance in foetal circulation, an observation that appears to be valid for our findings with both bPL and bPSPB. Increased bPL and bPSPB relative mRNA abundances in day-90 and day-180 placentomes and concentrations in the foetal plasma and allantoic fluid on day 90, along with accumulations of glucose and fructose in foetal plasma and associated fluids (Bertolini et al. 2004), were associated with an increase in prenanatal growth and foetal number in IVP concepti. As placentomes from IVP pregnancies were distinct from controls in terms of morphology, mass and surface area, the pattern of secretion of $\mathrm{BC}$ products may have been affected and explain some of the distinct patterns seen in IVP pregnancies.

The elevation in bPL in the third trimester of pregnancy coincides with the period of faster foetal growth and mammogenesis (Patel et al. 1996). In fact, newborn IVP calves coincidentally displayed higher birth weights and plasma bPL and fructose concentrations immediately after birth (Bertolini et al. 2002a, 2004). Conversely, maternal concentrations of bPL during phase III of pregnancy (Fig. 3) in the in vitro singleton group were lower than in vitro twin and in vivo singleton groups and, at parturition, maternal bPL concentrations in in vivo-produced pregnancies fell earlier than in those that were in vitro derived (Fig. 3). Interestingly, Miles et al. (2004) reported a reduction in foetal villi and BC volume densities in day-222 IVF-derived placentomes, which coincides with the period of decrease in maternal bPL levels in females carrying IVP singleton foetuses in this study.

Evidence exists that protein expression in BCs is affected by anatomical location (Wooding et al. 1996, Patel et al. $2004 b$ ), and such differences in synthetic capacity appear to be more under maternal than foetal influence, since both cotyledonary and intercotyledonary tissues are exposed to a similar foetal environment (Wooding et al. 1996). The presence of higher concentrations of bPL in IVP calves in the first hour after birth, along with higher concentrations in the allantoic fluid, suggests that a 'leakage' occurs from placental tissue to the foetal circulation, since no or negligible transfer of PL appears to occur from the maternal to the foetal circulation in sheep (Reddy \& Watkins 1983). Such findings corroborate the concept that the pattern of secretion of bPL in the foetal circulation may be relevant for foetal growth (Byatt et al. 1992a) and disturbances in placental formation may lead to such differential pattern of bPL secretion between the maternal and uterine compartments (Ravelich et al. 2004).

In addition to placental mass, parity and nutrition also appear to modulate the secretion of bPL. However, Patel et al. (1996) did not find distinctions in maternal bPL concentrations between singleton- and twin-bearing pregnancies, which the authors explained as a reduced placental mass per foetus in twin-bearing pregnancies. For singleton-bearing pregnancies, a relationship exists 
between placental and neonatal birth weights and maternal bPL concentrations, which could be used as a marker for conceptus development, viability and predicting abnormal birth weights (Patel et al. 1996). The half-life for the recombinant bPL has been reported to be $7.5 \mathrm{~min}$ (Byatt et al. 1992b), which is shorter than for GH or PRL but, as native bPL is heavily glycosylated (Byatt et al. 1992a), a half-life similar to GH and PRL (20 to $30 \mathrm{~min}$ ) is expected, which is visible in plasma of newborn calves in the first $60 \mathrm{~min}$ following birth (Fig. 5a). Conversely, as bPSPB has a rather long half-life, with its plasma levels still detectable 3 months or more after parturition (Sasser et al. 1986, Kiracofe et al. 1993), neonatal plasma concentrations remained elevated throughout the period under scrutiny $(24 \mathrm{~h})$ following parturition (Fig. 5b). However, differences in plasma clearance perhaps highlight bPL as a more dependable marker for pregnancy normalcy than bPSPB.

Many of the changes in placental development and function in the IVP group in this study were associated with the accelerated pattern of foetal growth, the delivery of larger calves, and the appearance of aberrant foetal membranes at term, and an increase in substrate uptake and protein synthetic capacity in IVP pregnancies (Bertolini et al. 2002a, 2004). Concentrations of bPL and bPSPB in foetal plasma were correlated with physical traits and with one another in foetal plasma and associated fluids irrespective of the experimental groups. Differential patterns of secretion of bPL and bPSPB into the maternal and foetal systems occurred at distinct stages of gestation, which were associated with altered conceptus development after in vitro embryo manipulations, indirectly demonstrating differences in placental function in IVP pregnancies. However, bPSPB/bPL prenatal measurements in foetal plasma and fluids were useful indicators of abnormal growth and development, but such invasive measurements lack a practical application.

\section{Acknowledgements}

The authors thank Dr R Garth Sasser for his advice and discussions regarding the bPSPB/bPAG-1 data. We also thank

$\mathrm{Dr} T \mathrm{R}$ Famula for his excellent assistance in the statistical analyses, AL Moyer, ML Sween and DJ Kominek for their technical assistance, and students and staff at the Beef Cattle Facilities of the Department of Animal Science and the Sierra Foothill Research and Extension Center of the University of California. Funding for the study was provided by the USDA W-112 Multi-State Research Project. M Bertolini was supported by a fellowship from CNPq/Brazil and by the Austin Eugene Lyons Graduate Fellowship from UC Davis. The authors declare that there is no conflict of interest that would prejudice the impartiality of this scientific work.

\section{References}

Anthony RV, Pratt SL, Liang R \& Holland MD 1995 Placental-fetal interactions: impact on fetal growth. Journal of Animal Science $\mathbf{7 3}$ $1861-1871$.
Austin KJ, King CP, Vierk JE, Sasser RG \& Hansen TR 1999 Pregnancy-specific protein $B$ induces release of an alpha chemokine in bovine endometrium. Endocrinology 140 542-545.

Behboodi E, Anderson GB, BonDurant RH, Cargill SL, Kreuscher BR, Medrano JF \& Murray JD 1995 Birth of large calves that developed from in vitro-derived bovine embryos. Theriogenology $\mathbf{4 4}$ $227-232$.

Bertolini M, Mason JB, Beam SW, Carneiro GF, Sween ML, Moyer AL, Famula TR, Sainz RD \& Anderson GB 2002a Morphology and morphometry of in vivo- and in vitro-produced bovine concepti from early pregnancy to term and association with high birth weights. Theriogenology 58 973-994.

Bertolini M, Beam SW, Shim H, Bertolini LR, Moyer AL, Famula TR \& Anderson GB $2002 b$ Growth, development and gene expression by in vivo- and in vitro-produced day-7 and day- 16 bovine embryos. Molecular Reproduction and Development 63 318-328.

Bertolini M, Moyer AL, Mason JB, Batchelder CA, Hoffert KA, Bertolini LR, Carneiro GF, Cargill SL, Famula TR, Calvert CC, Sainz RD \& Anderson GB 2004 Evidence of increased substrate availability to in vitro-derived bovine foetuses and association with accelerated conceptus growth. Reproduction 128 341-354.

Butler JE, Hamilton WC, Sasser RG, Ruder CA, Hass GM \& Williams RJ 1982 Detection and partial characterization of two bovine pregnancy-specific proteins. Biology of Reproduction 26 925-933.

Byatt JC, Warren WC, Eppard PJ, Staten NR, Krivi GG \& Collier RJ 1992a Ruminant placental lactogens: structure and biology. Journal of Animal Science 70 2911-2923.

Byatt JC, Eppard PJ, Veenhuizen JJ, Sorbet RH, Buonomo FC, Curran DF \& Collier RJ $1992 b$ Serum half-life and in vivo actions of recombinant bovine placental lactogen in the dairy cow. Journal of Endocrinology 132 185-193.

Corbacho AM, Martinez De La Escalera G \& Clapp C 2002 Roles of prolactin and related members of the prolactin/growth hormone/placental lactogen family in angiogenesis. Journal of Endocrinology 173 219-238.

Del Vecchio RP, Sasser RG \& Randel RD 1990 Effect of pregnancyspecific protein B on prostaglandin F2 and prostaglandin E2 by day 16-perifused bovine endometrial tissue. Prostaglandin 40 271-282.

Del Vecchio RP, Sutherland WD \& Sasser RG 1995 Effect of pregnancy-specific protein B on luteal cell progesterone, prostaglandin, and oxytocin production during two stages of the estrous cycle. Journal of Animal Science 73 2662-2668.

Del Vecchio RP, Sutherland WD \& Sasser RG 1996 Bovine luteal cells production in vitro of prostaglandin E2, oxytocin and progesterone in response to pregnancy-specific protein B and prostaglandin F2 alpha. Journal of Reproduction and Fertility $\mathbf{1 0 7}$ $131-136$.

Eiler H \& Hopkins FM 1993 Successful treatment of retained placenta with umbilical cord injections of collagenase in cows. Journal of the American Veterinary Medical Association 203 436-443.

Eley RM, Thatcher WW, Bazer FW, Wilcox CJ, Becker RB, Head HH \& Adkinson RW 1978 Development of the conceptus in the bovine. Journal of Dairy Science 61 467-473.

Gertler A \& Djiane J 2002 Mechanism of ruminant placental lactogen action: molecular and in vivo studies. Molecular Genetics and Metabolism 75 189-201.

Green JA, Xie S, Quan X, Bao B, Gan X, Mathialagan N, Beckers JF \& Roberts RM 2000 Pregnancy-associated bovine and ovine glycoproteins exhibit spatially and temporally distinct expression patterns during pregnancy. Biology of Reproduction 62 1624-1631.

Gootwine E 2004 Placental hormones and fetal-placental development. Animal Reproduction Science 82-83 551-566.

Gregoraszczuk EL, Zieba D, Wierzchos, Murawski M \& Gertler A 2000 Placental lactogen as a regulator of luteal function during pregnancy in sheep. Theriogenology 53 877-885.

Hashizume K, Ishiwata H, Kizaki K, Yamada O, Takahashi T, Imai K, Patel OV, Akagi S, Shimizu M, Takahashi S, Katsuma S, Shiojima 
S, Hirasawa A, Tsujimoto G, Todoroki J \& Izaike Y 2002 Implantation and placental development in somatic cell clone recipient cows. Cloning and Stem Cells 4 197-209.

Heyman Y, Chavette-Palmer, LeBourhis D, Camous S, Vignon X \& Renard JP 2002 Frequency and occurrence of late-gestation losses from cattle cloned embryos. Biology of Reproduction 66 6-13.

Hill JR, Burghardt RC, Jones K, Long CR, Looney CR, Shin T, Spencer TE, Thompson JA, Winger QA \& Westhusin ME 2000 Evidence for placental abnormality as the major cause of mortality in firsttrimester somatic cell cloned bovine fetuses. Biology of Reproduction 63 1787-1794.

Hill JR, Edwards JF, Sawyer N, Blackwell C \& Cibelli JB 2001 Placental anomalies in a viable cloned calf. Cloning 3 83-88.

Hoffert KA, Batchelder CA, Bertolini M, Moyer AL \& Anderson GB 2004 Angiogenesis in cloned and in IVF-derived bovine pregnancies at day 30 of gestation. Reproduction Fertility and Development 16143 (Abstract).

Holland MD, Hossner KL, Williams SE, Wallace CR, Niswender GD \& Odde KG 1997 Serum concentrations of insulin-like growth factors and placental lactogen during gestation in cattle. I. Fetal profiles. Domestic Animal Endocrinology 14 231-239.

Hossner KL, Holland MD, Williams SE, Wallace CR, Niswender GD \& Odde KG 1997 Serum concentrations of insulin-like growth factors and placental lactogen during gestation in cattle. II. Maternal profiles. Domestic Animal Endocrinology 14 316-324.

Ishiwata H, Katsuma S, Kizaki K, Patel OV, Nakano H, Takahashi T, Imai K, Hirasawa A, Shiojima S, Ikawa H, Suzuki Y, Tsujimoto G, Izaike Y, Todoroki J \& Hashizume K 2003 Characterization of gene expression profiles in early bovine pregnancy using a custom cDNA microarray. Molecular Reproduction and Development 65 9-18.

Kiracofe GH, Wright JM, Schalles RR, Ruder CA, Parish S \& Sasser RG 1993 Pregnancy-specific protein B in serum of postpartum beef cows. Journal of Animal Science 71 2199-2205.

Laven RA \& Peters AR 2001 Gross morphometry of the bovine placentome during gestation. Reproduction in Domestic Animals 36 289-296.

Leiser R, Krebs C, Klisch K, Ebert B, Dantzer V, Schuler G \& Hoffmann B 1997 Fetal villosity and microvasculature of the bovine placentome in the second half of gestation. Journal of Anatomy 191 517-527.

Leutenegger CM, Alluwaimi AM, Smith WL, Perani L \& Cullor JS 2000 Quantitation of bovine cytokine mRNA in milk cells of healthy cattle by real-time TaqMan ${ }^{\circledR}$ polymerase chain reaction. Veterinary Immunology and Immunopathology 77 275-387.

Lynch RA, Alexander BM \& Sasser RG 1992 The cloning and expression of the pregnancy-specific protein B. Biology of Reproduction 46 (Suppl 1) 72 (Abstract).

Miles JR, Farin CE, Rodriguez KF, Alexander JE \& Farin PW 2004 Angiogenesis and morphometry of bovine placentas in late gestation from embryos produced in vivo or in vitro. Biology of Reproduction 71 1919-1926.

Patel OV, Domeki I, Sasaki N, Takahashi T, Hirako M, Sasser RGU \& Humblot $\mathbf{P} 1995$ Effect of mass. number and stage of gestation on pregnancy-specific protein B concentrations in the bovine. Theriogenology 44 827-833.

Patel OV, Hirako M, Takahashi T, Sasaki N \& Domeki I 1996 Plasma bovine placental lactogen concentration throughout pregnancy in the cow; relationship to stage of pregnancy, fetal mass, number and postpartum milk yield. Domestic Animal Endocrinology 13 351-359.

Patel OV, Sulon J, Beckers JF, Takahashi T, Hirako M, Sasaki N \& Domeki I 1997 Plasma bovine pregnancy-associated glycoprotein concentrations throughout gestation in relationship to fetal number in the cow. European Journal of Endocrinology 137 423-428.

Patel OV, Yamada O, Kisaki K, Takahashi T, Imai K, Izaike Y, Schul LA, Takezawa T \& Hashizume K 2004a Expression of trophoblast cell-specific pregnancy-related genes in somatic cell-cloned bovine pregnancies. Biology of Reproduction 70 1114-1120.
Patel OV, Yamada O, Kizaki K, Todoroki J, Takahashi T, Imai K, Schuler LA \& Hashizume K 2004b Temporospatial expression of placental lactogen and prolactin-related protein-1 genes in the bovine placenta and uterus during pregnancy. Molecular Reproduction and Development 69 146-152.

Pedersen JF, Sorensen S \& Molsted-Pedersen L 1998 Serum levels of human placental lactogen, pregnancy-associated plasma protein A and endometrial secretory protein PP14 in first trimester of diabetic pregnancy. Acta Obstetricia et Gynecologica Scandinavica $77155-158$.

Penninga L \& Longo LD 1998 Ovine placentome morphology: effect of high altitude, long-term hypoxia. Placenta 19 187-193.

Perry VEA, Norman ST, Owen JA, Daniel RCW \& Phillips N 1999 Low dietary protein during early pregnancy alters bovine placental development. Animal Reproduction Science 55 13-21.

Prior RL \& Laster DB 1979 Development of the bovine fetus. Journal of Animal Science 48 1546-1553.

Ravelich SR, Shelling AN, Ramachandran A, Reddy S, Keelan JA, Wells DN, Peterson AJ, Lee RS \& Breier BH 2004 Altered placental lactogen and leptin expression in placentomes from bovine nuclear transfer pregnancies. Biology of Reproduction 71 $1862-1869$.

Reddy S \& Watkins WB 1983 Plasma clearance distribution of ${ }^{125}$ I-ovine placental lactogen in sheep. Australian Journal of Experimental Biology and Medical Science 61 301-311.

Reik W, Constancia M, Fowden A, Anderson N, Dean W, Ferguson-Smith A, Tycko B \& Sibley C 2003 Regulation of supply and demand for maternal nutrients in mammals by imprinted genes. Journal of Physiology 547 35-44.

Reynolds LP, Ferrell CL, Robertson DA \& Klindt J 1990 Growth hormone, insulin and glucose concentrations in bovine fetal and maternal plasmas at several stages of gestation. Journal of Animal Science 68 725-733.

Sasser RG, Ruder CA, Ivani KA, Butler JE \& Hamilton WC 1986 Detection of pregnancy by radioimmunoassay of a novel pregnancy-specific protein in serum of cows and a profile of serum concentrations during gestation. Biology of Reproduction 35 936-942.

Schlafer DH, Fisher PJ \& Davies CJ 2000 The bovine placenta before and after birth: placental development and function in health and disease. Animal Reproduction Science 60-61 145-160.

Schmidt M, Greve T, Avery B, Beckers JF, Sulon J \& Hansen HB 1996 Pregnancies, calves and calf viability after transfer of in vitro produced bovine embryos. Theriogenology 46 527-539.

Symonds ME, Budge H, Stephenson T \& McMillen IC 2001 Fetal endocrinology and development - manipulation and adaptation to long-term nutritional and environmental challenges. Reproduction $121853-862$.

Szenci O, Beckers JF, Humblot P, Sulon J, Sasser RG, Taverne MAM, Varga J, Baltusen R \& Schekk G 1998 Comparison of ultrasonography, bovine pregnancy-specific protein $B$, and bovine pregnancy-associated glycoprotein-1 tests for pregnancy detection in dairy cows. Theriogenology 50 77-88.

Szenci O, Beckers JF, Sulon J, Bevers MM, Borzsonyi L, Fodor L, Kovács F \& Taverne MAM 2003 Effect of induction of late embryonic mortality on plasma profiles of pregnancy associated glycoprotein 1 in heifers. Veterinary Journal 165 307-313.

Tefera M, Jeanguyot N, Thibier M \& Humblot P 2001 Pregnancyspecific protein B (bPSPB) and progesterone monitoring of post-partum dairy cows with placental retention. Journal of the American Veterinary Medical Association 48 331-336.

Vasquez MI, Horta AEM, Marques CC, Sasser RG \& Humblot P 1995 Levels of bPSPB throughout single and twin pregnancies after Al or transfer of IVM/IVF cattle embryos. Animal Reproduction Science 38 279-289.

Vatnick I, Schoknecht PA, Darrigrand R \& Bell AW 1991 Growth and metabolism of the placenta after unilateral fetectomy in twin pregnancy ewes. Journal of Developmental Physiology 15 351-356. 
Wallace CR 1993 Concentration of bovine placental lactogen in dairy and beef cows across gestation. Domestic Animal Endocrinology $1067-70$.

Wallace JM, Bourke DA \& Aitken RP 1999 Nutrition and fetal growth: paradoxical effects in the overnourished adolescent sheep. Journal of Reproduction and Fertility 54 Suppl. 385-399.

Wooding FBP 1992 The synepitheliochorial placenta of ruminants: binucleate cell fusions and hormone production. Placenta 13 $101-113$.

Wooding FBP, Morgan G, Monaghan S, Hamon M \& Heap RB 1996 Functional specialization in the ruminant placenta: evidence of two populations of fetal binucleate cells of different selective synthetic capacity. Placenta 17 75-86.

Xie S, Low BG, Nagel RJ, Kramer KK, Anthony RV, Zoli AP, Beckers JF \& Roberts RM 1991 Identification of the major pregnancy-specific antigens of cattle and sheep as inactive members of the aspartic proteinase family. PNAS $\mathbf{8 8}$ 10247-10251.

Xie S, Green J, Beckers JF \& Roberts RM 1995 The gene encoding bovine pregnancy-associated glycoprotein-1, an inactive member of the aspartic proteinase family. Gene 159 193-197.

Zoli AP, Becker JF, Wouters-Ballman P, Closset J, Falmagne P \& Ectors F 1991 Purification and characterization of a bovine pregnancy-associated glycoprotein. Biology of Reproduction 45 $1-10$.

Received 13 March 2005

First decision 5 May 2005

Revised manuscript received 8 July 2005

Accepted 16 August 2005 